\title{
Bioconversion of agricultural lignocellulosic residues into branched-chain fatty acids using Streptomyces lividans
}

\author{
Thierry Dulermo ${ }^{1,2}$, Fabien Coze ${ }^{1,2}$, Marie-Joëlle Virolle ${ }^{1,2}$, Valérie Méchin ${ }^{3,4}$, Stéphanie Baumberger ${ }^{3,4}$ \\ and Marine Froissard ${ }^{3,4, \star}$ \\ 1 CNRS UMR 8621, Institut de Génétique Moléculaire, 91405 Orsay, France \\ 2 Université Paris Sud, UMR 8621, Institut de Génétique Moléculaire, 91405 Orsay, France \\ 3 INRA, UMR 1318, Institut Jean-Pierre Bourgin, Saclay Plant Sciences, 78026, Versailles Cedex, France \\ 4 AgroParisTech, UMR 1318, Institut Jean-Pierre Bourgin, Saclay Plant Sciences, 78026, Versailles Cedex, France
}

Received 3 juillet 2015 - Accepted 7 septembre 2015

\begin{abstract}
Two lignocellulosic agricultural residues, sunflower stalks and rape straw, were investigated as potential low-cost, non-food substrates for the production of triacylglycerols by the oleaginous, lignocellulolytic bacteria Streptomyces lividans. Chemical analysis of each type of residue revealed similar cell wall compositions in the polysaccharides and lignins of the two feedstocks, with high lignin $\beta$-O-4 bond content compared to other angiosperms' lignin. Growing tests of Streptomyces lividans TK 24 were performed before and after sequential water and ethanol extraction by assessing bacterial fatty acid accumulation. All extracted and non-extracted samples were found to be substrates of the bacteria with fatty acid production ranging between $19 \%$ and $44 \%$ of the production obtained with arabinose as a reference substrate. The maximum conversion rate was obtained with the less lignified, non-extracted sample. This study suggests that lignocellulosic residues from oleaginous crops could be advantageously valorized by microbial bioconversion processes for the production of lipids of interest.
\end{abstract}

Keywords: Streptomyces / rapeseed / sunflower / fatty acids / lignocellulose

Résumé - Deux types de résidus issus de l'agriculture, des tiges de tournesol et des pailles de colza, ont été étudiés afin d'évaluer leur potentiel comme substrat non alimentaire et à faible coût pour la production de triacylglycérol par Streptomyces lividans, une bactérie oléagineuse et lignocellulolytique. Une analyse chimique de chaque résidu a montré une composition des parois en polysaccharides et lignines identique avec un fort taux de liaison $\beta$-O- 4 , contrairement aux lignines des autres angiospermes. Des tests de croissance de la souche TK24 de Streptomyces lividans ont été effectués sur les résidus avant et après extraction séquentielle à l'eau et à l'éthanol. La croissance a été évaluée en mesurant l'accumulation des acides gras bactériens. Tous les résidus se sont révélés être des substrats pour la bactérie, avec une production allant de $19 \%$ à $44 \%$ de la production de référence obtenue sur arabinose. Le maximum de conversion a été obtenu sur le résidu le moins lignifié et non extrait. Cette étude suggère que les résidus lignocellulosiques des plantes oléagineuses de grande culture peuvent être valorisés de manière avantageuse en lipides d'intérêt par des procédés de bioconversion microbiologique.

Mots clés : Streptomyces / colza / tournesol / acides gras / lignocellulose

\section{Introduction}

Lipid-based chemicals and biofuels are of great interest in the current context of petroleum resource rarefaction. At present, the lipids used for green chemistry and energy are mostly triacylglycerols (TAG) extracted from crop seeds or animal fats (Octave and Thomas, 2009). Because of the competition with food usage, the use of these lipid sources is ques-

\footnotetext{
* Correspondence: marine. froissard@versailles.inra.fr
}

tionable. Scientists and industries are working collaboratively to identify and develop alternative renewable sources of lipids for non-food use. In the past decade, oleaginous single-cell microorganisms have reached the forefront of this research because of their high efficiency for TAG production or storage (Garay et al., 2014; Liu et al. 2013). For most, their lipid metabolic and biochemical pathways have been identified and their growth on refined simple carbon sources is well-described (Blazeck et al., 2014; Comba et al., 2013). However, their optimal valorization in cost-effective processes 
necessitates the optimization of their growth on less expensive substrates, such as wastes or lignocellulosic residues.

Lignocellulose constitutes the main part of plant biomass and is available either as a byproduct of the agriculture and food industries (brans and stems) or as dedicated biomass feedstocks (wood and fiber crops). Thus, it represents an important, renewable carbon pool for the production of bioenergy (Somerville et al., 2010) and biomolecules of interest, in particular by bacterial bioconversion (Mathews et al., 2015). Efficient exploitation remains challenging because this biomass is complex (Menon and Rao, 2012). Indeed, the lignocellulose of the secondary, lignified plant cell wall is composed of an interpenetrated assembly of three polymers: cellulose, hemicelluloses, and lignin. While cellulose and hemicelluloses are easily converted into sugars by enzymes, the presence of lignin, a hydrophobic phenolic polymer, is responsible for lignocellulose's overall recalcitrance to the enzymatic deconstruction processes (Zhao et al., 2012).

The objective of this study was to assess the possibility of converting lignocellulose into lipids of interest for industrial use with microorganisms known for their wood-degrading activity and constituent lignin-degrading enzymes. For this study, oilseed crop lignocellulosic residues, i.e., sunflower stalks and rapeseed straw, were chosen, as they are abundant, oleaginous coproducts in Europe and seem to be promising sources of biomass for biofuel and paper production (Mazhari Mousavi et al., 2013; Ziebell et al., 2013). Because data regarding their chemical compositions are rare, structural analyses useful for their optimal valorization in biorefinery processes were carried out. To assess the potential of these materials to be used as substrates for lipid production, Streptomyces, a Gram-positive filamentous soil bacteria, was used for growth and bioconversion tests. Bacteria of this genus are well-known for their natural ability to degrade lignocellulose because their genomes possess enzymatic pathways involved in the degradation and catabolism of lignin residues (Davis and Sello 2010; Davis et al., 2012). Indeed, bacteria belonging to the actinomycetes group are of great interest in the context of bioconversion of lignocellulose into high-value bioproducts. Some species, such as Rhodococcus and Streptomyces, are described as oleaginous and can accumulate more than $20 \%$ of their dry weight as TAG (Alvarez and Steinbuchel 2002; Deniset-Besseau et al., 2014; Olukoshi and Packter 1994). Rhodococcus was shown to be able to accumulate up to $87 \%$ of its dry weight as TAG when grown using olive oil as the substrate (Alvarez et al., 1996). Recently, Rhodococcus was engineered to produce TAG using lignocellulosic residues as substrates. R. opacus DSM 1069 and PD630 are able to convert lignin into TAG (Kosa and Ragauskas, 2012). Efforts have also been devoted to constructing strains capable of utilizing xylose, an abundant sugar in lignocellulosic residues. A xylose-fermenting Rhodococcus strain was constructed using heterologous expression of the Streptomyces enzymes involved in the xylose metabolism pathway (Kurosawa et al., 2013; Xiong et al., 2012). Interestingly, the Streptomyces species has the natural capacity to grow on and catabolize the phenolic compounds and polysaccharides present in lignocellulose (Antai and Crawford 1981; Crawford 1978; Davis and Sello 2010; Vetrovsky et al., 2014). In addition, Streptomyces species, historically studied and ex- ploited for antibiotic production, can also accumulate TAG under specific nutritional conditions (high $\mathrm{C} / \mathrm{N}$ ratios) (Arabolaza et al., 2008; Comba et al., 2013; Le Marechal et al., 2013).

In this study, the capacity of Streptomyces lividans TK 24 to grow on agricultural lignocellulosic residues from Brassica napus and Helianthus annuus, some of the main oleaginous crops in Europe, was investigated. The polysaccharide, lignin, and fatty acid contents of these unconventional fermentation substrates were first assessed. Then, bacterial cultures in the presence of these substrates were performed and their growth was determined using bacterial fatty acid content as a biomarker. The production of bacterial fatty acids using these substrates was demonstrated, revealing that these lignocellulosic residues could be valorized in bioconversion processes with these microorganisms.

\section{Material and methods}

\subsection{Lignocellulosic feedstocks}

Brassica napus (Rapeseed, Rap1 and Rap2 samples) and Helianthus annuus (Sunflower, Sun1 and Sun2 samples) agricultural samples (straws or stalks) were provided by the Organisation Nationale Interprofessionnelle des Graines et Fruits Oléagineux (Onidol, France). They were ground with a hammer mill to pass through a $1-\mathrm{mm}$ screen. Pictures of the lignocellulosic samples were obtained using an illuminated binocular magnifier (Nikon SMZ800) and a Nikon Coolpix 4500 digital camera.

\subsection{Strains, media, and culture conditions}

The strain used throughout this study was Streptomyces lividans TK24. Lignocellulosic substrates (1.2 g) were sterilized with $19 \mathrm{ml}$ of water in 150-ml growth flasks, and $1 \mathrm{ml}$ of minimal medium without glucose. (Coze et al., 2013) was added to obtain a final volume of $20 \mathrm{ml}$. Inoculations were done with $3 \times 10^{8}$ spores per flask. Positive growth controls (without lignocellulosic substrates) were made using 2\% (v/v) glucose, arabinose, or xylose as the carbon sources. Cultures were performed for 6 days at $30{ }^{\circ} \mathrm{C}$ while shaking at $200 \mathrm{rpm}$.

\subsection{Lignocellulose fractionation}

Lignocellulosic feedstocks (5 g) were sequentially extracted using an accelerated solvent extraction device (ASE 350, Dionex, USA). Extraction was performed following a two-step procedure (Fig. 1); the first step was with water (total volume, $200 \mathrm{ml}$ ), and the second step was with ethanol (total volume, $110 \mathrm{ml}$ ). Each step was performed using three 7-min extraction cycles at $100{ }^{\circ} \mathrm{C}$ and 110 bar under a nitrogen atmosphere. In parallel, the feedstocks were submitted to a singlestep water extraction. The remaining residues were dried in an oven at $50{ }^{\circ} \mathrm{C}$ for $48 \mathrm{~h}$ (until constant mass was achieved), and the water and ethanol supernatants were stored at $-20{ }^{\circ} \mathrm{C}$.

Extractions were performed in duplicate for each initial sample. The water extractives and total extractives contents 


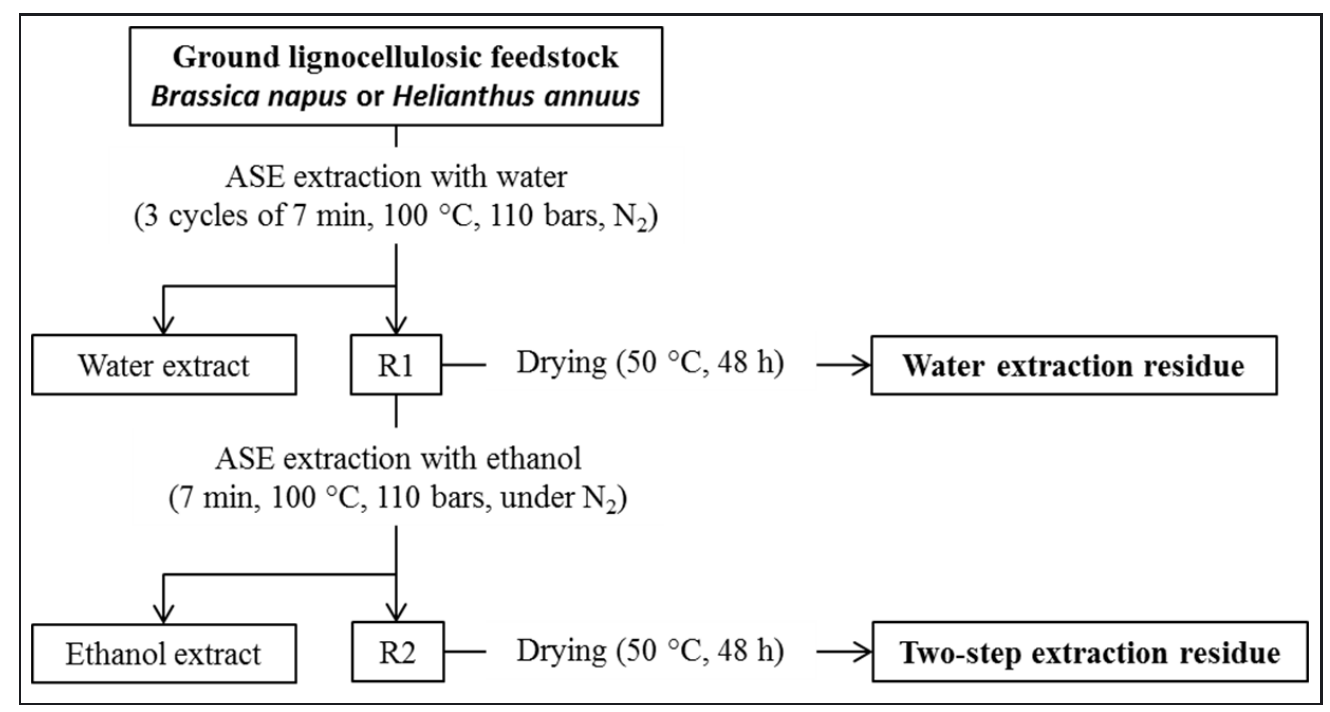

Fig. 1. Scheme of two-step accelerated solvent extraction (ASE) procedure for the recovery of water and water-ethanol total extractives.

were calculated from the weight mass loss and expressed with respect to the total initial dry weight using the following equations:

$$
\begin{aligned}
& \% \text { water extractives } \\
& =\frac{\text { initial mass }- \text { mass of water extraction residue }}{\text { initial mass }} \times 100
\end{aligned}
$$

\section{$\%$ total extractives}

$$
=\frac{\text { initial mass }- \text { mass of two step extraction residue }}{\text { initial mass }} \times 100
$$

For each sample, the results were calculated as the mean values and standard deviation of the averages obtained for both duplicates.

\subsection{Lignocellulose characterization}

All of the following analyses were performed in duplicate on the residues of two distinct extractions from each initial sample. For each sample, the results were calculated as the mean values and standard deviation of the averages obtained for both duplicates.

\subsubsection{Lignin quantification}

The lignin content of the two-step extraction residues was determined using the standard Klason method (Dence and Lin, 1992). The samples (300 mg) were suspended in $3 \mathrm{ml}$ of sulfuric acid solution $(72 \% \mathrm{p} / \mathrm{v})$ for $2 \mathrm{~h}$ at $20{ }^{\circ} \mathrm{C}$ before being diluted to a $5 \% \mathrm{p} / \mathrm{v}$ final sulfuric acid concentration and heated under reflux for $4 \mathrm{~h}$. The reaction mixture was filtered on a glass microfiber filter, and the remaining material was dried in an oven at $100{ }^{\circ} \mathrm{C}$ for $12 \mathrm{~h}$. The lignin content was calculated from the mass of the final solid material after correction for its ash content.

\subsubsection{Lignin structural analysis}

Lignin structure evaluation was performed on the two-step extraction residues ( 5 to $10 \mathrm{mg}$ ) using the thioacidolysis procedure (Lapierre et al., 1995). The determination of the main p-hydroxyphenyl $(\mathrm{H})$, guaiacyl $(\mathrm{G})$, and syringyl (S) ligninderived monomers involved in $\beta$-O-4 bonds, analyzed as their trimethylsilylated (TMS) derivatives, was carried out using specific ion chromatograms reconstructed at $\mathrm{m} / \mathrm{z} 239$ for $\mathrm{H}$ monomers, 269 for $\mathrm{G}$ monomers, and 299 for $\mathrm{S}$ monomers.

\subsubsection{Sugar quantification}

The neutral sugar contents were determined by highperformance ion exchange chromatography (column: $4 \times$ $250 \mathrm{~mm}$, Carbopac PA1, Dionex, USA; eluent: 4 mM sodium hydroxide, $1 \mathrm{ml} / \mathrm{min}$ ) using a pulsed amperometric detector. The initial feedstock, water extraction residues, and two-step extraction residues were submitted to acidic hydrolysis prior to sugar analysis. The samples $(10 \mathrm{mg})$ were suspended in $125 \mu \mathrm{l}$ of a $72 \%(\mathrm{p} / \mathrm{v})$ sulfuric acid solution for $1 \mathrm{~h}$ at ambient temperature and then $100{ }^{\circ} \mathrm{C}$ for $2 \mathrm{~h}$ before filtration of the reaction mixture as described above. The sugar content was calculated using fucose as an internal standard.

\subsection{Determination of fatty acid content in feedstocks before and after Streptomyces growth}

Samples were freeze-dried for $72 \mathrm{~h}$ and then heated for $90 \mathrm{~min}$ at $80{ }^{\circ} \mathrm{C}$ in the presence of $16 \mathrm{ml}$ of $2.5 \%$ (v/v) sulfuric acid in methanol. Dodecanoic acid (Sigma-Aldrich) was added (400 $\mu$ g for each sample) as the internal standard for quantification. Fatty acid methyl esters (FAME) were extracted via the addition of $24 \mathrm{ml}$ of $150 \mathrm{mM} \mathrm{NaCl}, 2.5 \mathrm{ml}$ of hexane, vigorous shaking, and centrifugation at $1000 \mathrm{~g}$ for $15 \mathrm{~min}$. The organic upper phase of the samples was separated by gas chromatography using a 7890A chromatograph (Agilent, USA) with a 


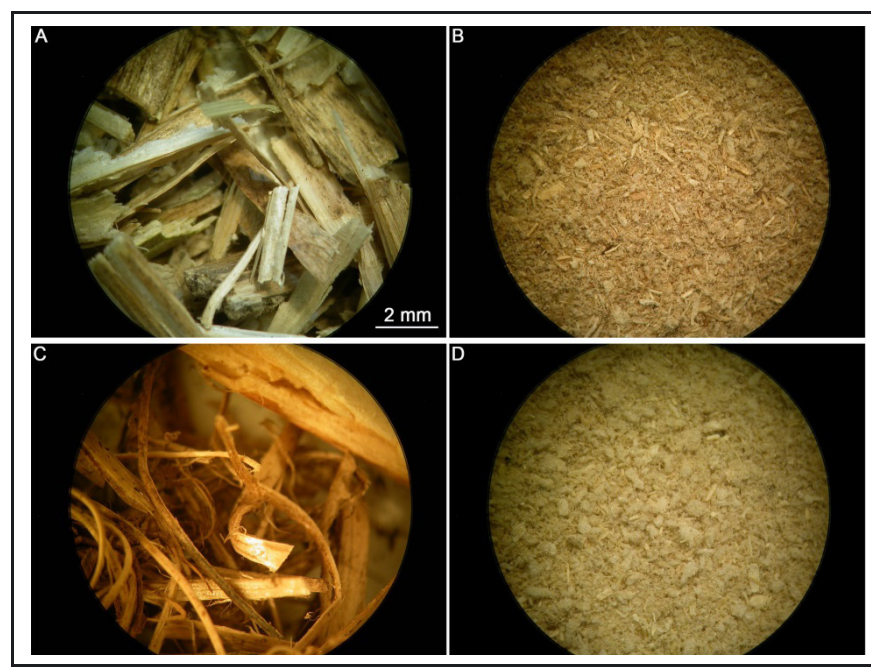

Fig. 2. Macroscopic observation of oleaginous lignocellulosic residues. Rapeseed straw (A, B) and sunflower stalk (C, D) agricultural residues were observed before $(\mathrm{A}, \mathrm{C})$ and after $(\mathrm{B}, \mathrm{D})$ grinding with a hammer mill to obtain residues with sizes compatible with biochemical analysis and Streptomyces growth tests.

Factor Four VF-23 ms 30-m × 0.25-mm capillary column $(\mathrm{Ag}-$ ilent, USA). The carrier gas was helium at an inlet flow rate of $1 \mathrm{ml} / \mathrm{min}$. The column temperature began at $40{ }^{\circ} \mathrm{C}$ for $1 \mathrm{~min}$, ramped to $130{ }^{\circ} \mathrm{C}$ at $40^{\circ} \mathrm{C} / \mathrm{min}$, remained at $130{ }^{\circ} \mathrm{C}$ for $1 \mathrm{~min}$, ramped to $160{ }^{\circ} \mathrm{C}$ at $1{ }^{\circ} \mathrm{C} / \mathrm{min}$, remained at $160{ }^{\circ} \mathrm{C}$ for $1 \mathrm{~min}$, ramped to $210^{\circ} \mathrm{C}$ at $40{ }^{\circ} \mathrm{C} / \mathrm{min}$, and finally remained at $210^{\circ} \mathrm{C}$ for $4 \mathrm{~min}$. Identification of FAME peaks was based on retention times obtained for standards (FAME mix from SigmaAldrich and GLC-110 mix from Biovalley). The quantification was made via flame ionization detection at $270{ }^{\circ} \mathrm{C}$. The total amount of fatty acids was calculated from the ratio between the sum of the FAME peak areas and the dodecanoic acid methyl ester peak area.

\subsection{Microscopy observations}

Streptomyces cultures on lignocellulosic residues were monitored using a Zeiss Axio Imager microscope (Germany) with Nomarski optics and a Roper CoolSnap HQ2 camera (USA) coupled to a Zeiss AxioVision driver.

\section{Results and discussion}

\subsection{Biomass pretreatments}

Rapeseed straw and sunflower stalks (two batches for each species) were obtained from the agricultural stocks. The size of the crop product pieces ranged from a few millimeters to several tens of centimeters (Figs. 2A and 2C). To reduce heterogeneity and obtain substrates compatible with chemical analysis and Streptomyces growth tests, pretreatments of the biomaterials were performed. First, the samples were crushed to homogenize them and reduce the size of their fragments (up to $1 \mathrm{~mm}$, as shown in Figs. 2B and 2D) to optimize component extraction and increase surface contact with the Streptomyces mycelium. Second, sequential extractions with water and ethanol were performed. The objective of the extraction was to recover extractive-free residues as required for the analysis of the cell wall components (lignin and polysaccharides) and to assess the influence of soluble compounds on Streptomyces growth.

\subsection{Composition of the lignocellulosic feedstocks and residues}

\subsubsection{Extractives}

Rapeseed straw and sunflower stalk contained $19.3 \%$ and $26.1 \%$ water extractives, respectively, on average. A subsequent extraction with ethanol removed $1.5 \%$ and $1 \%$ of the soluble compounds from these feedstocks, respectively (Tab. 1).

\subsubsection{Lignin content and structure}

The lignin contents of rapeseed straw and sunflower stalk were $17.4 \%$ and $15.6 \%$, respectively, based on the average of two batches (Tab. 1). These values are in the range of lignin contents found for other agro-resource stems (13\% to $22 \%$ according to Mood et al., 2013) but lower than that of wood (Dence and Lin, 1992). They are in agreement with other data available for sunflower (13.4\% according to Mood et al. 2013, $19.9 \%$ according to Caparrós et al. 2008, and $18.3 \%$ according to Mazhari Mousavi et al., 2013) and rapeseed stalk (16.0\% according to Mazhari Mousavi et al., 2013). However, Kang et al. (2012) reported a lower lignin content, 6.9\%, for rapeseed stem. These variations can be explained by differences in the developmental stages of the harvested material, as previously observed for maize (Boon et al., 2012; Jung and Casler 2006). Among the different methods available for lignin structural analysis, thioacidolysis followed by GC-MS analysis of the depolymerization monomers reveals both the proportion of the different constitutive units and the frequency of interunit linkages of the $\beta$ aryl ether type. Indeed, thioacidolysis selectively cleaves these linkages, releasing monomers and oligomers only linked by resistant bonds. Yields of the different monomer types recovered after thioacidolysis, expressed with respect to lignin mass, gave indications as to the proportions of units linked by labile ether bonds. This structural parameter, in addition to giving an indication of the global lignin content, is likely to influence the cell wall properties and the bioconversion of lignocellulose. Indeed, Zhang et al. (2011) discovered a negative correlation between thioacidolysis yield and the enzymatic degradability of maize stems using a commercial cellulolytic cocktail.

All samples were found to have similar lignin structures with the presence of both guaiacyl (G) and syringyl (S) units, as in all angiosperms, with rather high $\mathrm{S} / \mathrm{G}$ ratio (1.7) and total thioacidolysis yield (2000 to $2500 \mu \mathrm{mol} / \mathrm{g}$ ). The $\mathrm{S} / \mathrm{G}$ ratio was in the range of ratios previously observed for sunflower by high-throughput pyrolysis molecular beam mass spectrometry ( 1 to 2 for various $H$. annuus samples; Ziebell et al., 2013) and is close to that of most hardwoods (Dence and Lin, 1992). 
Table 1. Composition (\% dry basis; mean (standard deviation)) and lignin characteristics of rapeseed straw (Brassica napus) and sunflower stalks (Helianthus annuus).

\begin{tabular}{ccccc}
\hline Components & \multicolumn{2}{c}{ Rapeseed straw } & \multicolumn{2}{c}{ Sunflower stalks } \\
\hline Extractives & Rap1 & Rap2 & Sun1 & Sun2 \\
\hline Water extractives & & & & \\
Total water-ethanol extractives & $21.8(0.3)$ & $16.7(2.8)$ & $27.3(0.8)$ & $24.8(1.0)$ \\
Non water-soluble ethanol extractives & 0.9 & 2.1 & 1.2 & 0.8 \\
\hline Lignin & & & & \\
Klason lignin content & $17.2(0.1)$ & $17.6(0.1)$ & $14.0(0.4)$ & $17.2(0.5)$ \\
S/G Ratio & $1.5(0.0)$ & $1.3(0.0)$ & $1.3(0.0)$ & $1.4(0.0)$ \\
Total thioacidolysis yield $(\mu$ mol/g KL) & $2417(233)$ & $2527(283)$ & $2544(215)$ & $2253(130)$ \\
\hline Cellulose & & & & \\
& $32.2(1.4)^{\mathrm{a}}$ & $30.4(0.9)^{\mathrm{a}}$ & $34.0(2.1)^{\mathrm{a}}$ & $31.8(0.2)^{\mathrm{a}}$ \\
& $33.7(2.4)^{\mathrm{b}}$ & $31.4(1.9)^{\mathrm{b}}$ & $33.3(2.4)^{\mathrm{b}}$ & $34.3(2.3)^{\mathrm{b}}$ \\
& $25.2^{\mathrm{c}}$ & $25.3^{\mathrm{c}}$ & $24.7^{\mathrm{c}}$ & $23.9^{\mathrm{c}}$ \\
\hline Non water soluble hemicelluloses & & & & \\
& $17.2(1.1)^{\mathrm{a}}$ & $16.9(0.9)^{\mathrm{a}}$ & $17.4(1.2)^{\mathrm{a}}$ & $14.9(0.3)^{\mathrm{a}}$ \\
& $18.2(1.4)^{\mathrm{b}}$ & $17.1(1.0)^{\mathrm{b}}$ & $17.2(1.4)^{\mathrm{b}}$ & $16.2(1.4)^{\mathrm{b}}$ \\
& $13.4^{\mathrm{c}}$ & $14.0^{\mathrm{c}}$ & $12.6^{\mathrm{c}}$ & $11.2^{\mathrm{c}}$ \\
\hline
\end{tabular}

${ }^{\mathrm{a}}$ In water extraction residue. ${ }^{\mathrm{b}}$ In two-step extraction residue. ${ }^{\mathrm{c}}$ In unextracted material (calculated from the content in the water extraction residue).

The thioacidolysis yield indicates an uncommonly high proportion of ether bonds, as observed for Eucalyptus globulus (Guerra et al., 2008). Considering that the average molar mass of a lignin unit is $200 \mathrm{~g} / \mathrm{mol}$, it can be calculated that about $50 \%$ of the units are only involved in aryl ether bonds. This suggests that such lignins are likely to depolymerize more easily than grass lignins, which contain lower proportions of aryl ether bonds. Indeed, aryl ether bonds are known as labile bonds, less resistant to chemical and biological attacks than other lignin inter-unit bonds. However, they may limit bioconversion of polysaccharides because of the barrier effect, as previously observed for maize (Zhang et al., 2011).

\subsubsection{Polysaccharide composition}

Glucose and xylose were the main neutral sugars recovered after acidic hydrolysis of rapeseed straw and sunflower stem samples (more than $90 \mathrm{wt} \%$ of the total neutral sugars). In addition to these two sugars, galactose, arabinose, and mannose were detected. Assuming that glucose is primarily derived from cellulose and other sugars from hemicelluloses, the cellulose and hemicellulose contents in the initial feedstocks and extraction residues were calculated as the anhydroglucose and total other anhydrosugar contents, respectively (Tab. 1). Little variation was observed between the different extraction residues, with cellulose content ranging from $30.4 \%$ to $34.3 \%$ and hemicelluloses content ranging from $14.4 \%$ to $18.2 \%$. These values are in agreement with the data reported by Ziebell et al., (2013) for H. annuиs (32.8\% and 15.9\%, respectively). The cellulose contents are lower than those reported by Mazhari Mousavi et al. (2013) for rapeseed straw and sunflower stalks as a result of the use of a different determination method. These authors did not determine the hemicellulose content.

\subsubsection{Fatty acid composition}

FA profiling of the lignocellulosic substrates was also conducted. Identification of the FA contained in these substrates was essential for further growth tests, as it was not possible to separate the bacterial biomass from the plant biomass (see below). FA quantification after growth tests was performed on bacterial-specific FA to exclude common FA from the quantification. FA profiling was done on $50 \mathrm{mg}$ of freeze-dried, 1-mm lignocellulosic residues. It was observed that the samples contained saturated and unsaturated FA with lengths of 14 or more carbons (C14:0, C14:1, C16:0, C16:1, C18:0, C18:1, C18:2, $\mathrm{C} 18: 3, \mathrm{C} 20: 0$, and C22:0).

\subsection{Growth tests on lignocellulosic residues}

\subsubsection{Strain behavior}

Streptomyces species have long been studied for their capacity to produce interesting bioactive molecules (antibiotics, anti-cancer and anti-obesity drugs, insecticides, herbicides, and others), but their ability to store TAG has been largely overlooked, even though ancient work reports this ability (Olukoshi and Packter, 1994). In a recently published work, it was observed that Streptomyces lividans TK24, which produces little to no antibiotics, has a better capacity to store TAG than Streptomyces coelicolor, a strong antibiotic producer (Le Marechal et al., 2013). For this reason, S. lividans TK 24 was selected to evaluate the feasibility of bioconversion of lignocellulose into bacterial lipids. Bacterial growth was assessed by evaluating the total bacterial FA content obtained after 6 days of cultivation. To do so, it was essential to identify the specific bacterial FA using various monosaccharides as substrates. FA analysis of bacteria grown on arabinose (Fig. 3A), glucose (Fig. 3B), and xylose (Fig. 3C) was performed to determine the variability of the FA profiles of cells grown on 
Table 2. Bacterial fatty acid content in cultures performed on arabinose, rapeseed straw (Rap1 and Rap2), and sunflower stalks (Sun1 and Sun2) (expressed as $\mu \mathrm{g}$ of fatty acid methyl esters per $3 \times 10^{8}$ Streptomyces spores).

\begin{tabular}{ccccc}
\hline Substrate & Negative control & Without extraction & Water extraction & Water + ethanol extraction \\
\hline Arabinose & 64 & 1632 & & \\
\hline Rap1 & 104 & 305 & 298 & 280 \\
Rap2 & 46 & 302 & 336 & 334 \\
Sun1 & 74 & 717 & 427 & 388 \\
Sun2 & 49 & 509 & 553 & 572 \\
\hline
\end{tabular}

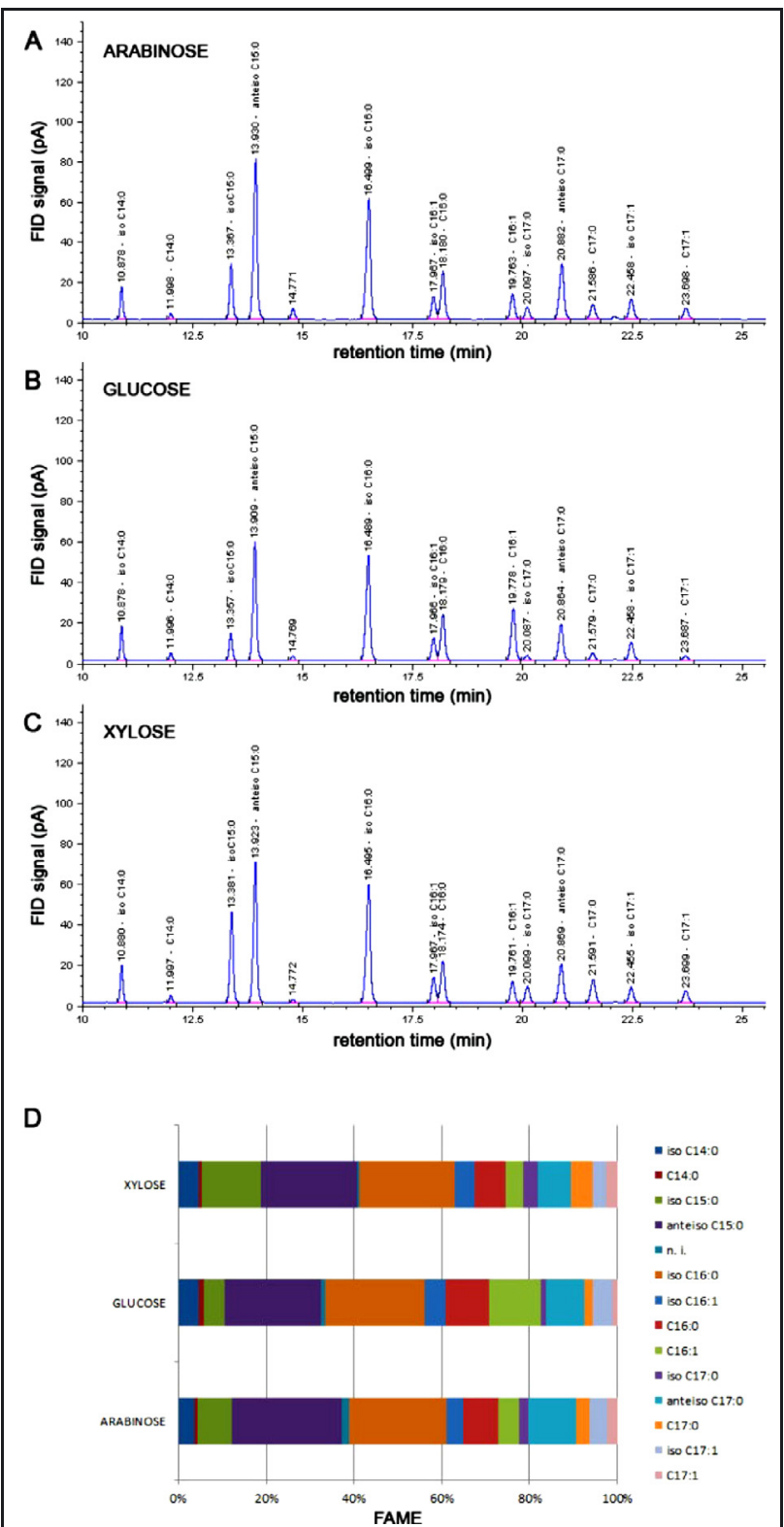

Fig. 3. Fatty acid profiling of Streptomyces lividans grown on monosaccharides. After $6 \mathrm{~d}$ of culture at $30{ }^{\circ} \mathrm{C}$ in the presence of monosaccharides as the carbon source, Streptomyces cultures were freeze-dried and the samples were submitted to transmethylation. The FAME obtained on (A) arabinose, (B) glucose, and (C) xylose were analyzed using gas chromatography coupled with flame ionization detection (D) Relative fatty acid profiling was plotted for each carbon source. Abbreviations: FID, Flame Ionization Detection; FAME, fatty acid methyl esters; n.i., not identified.

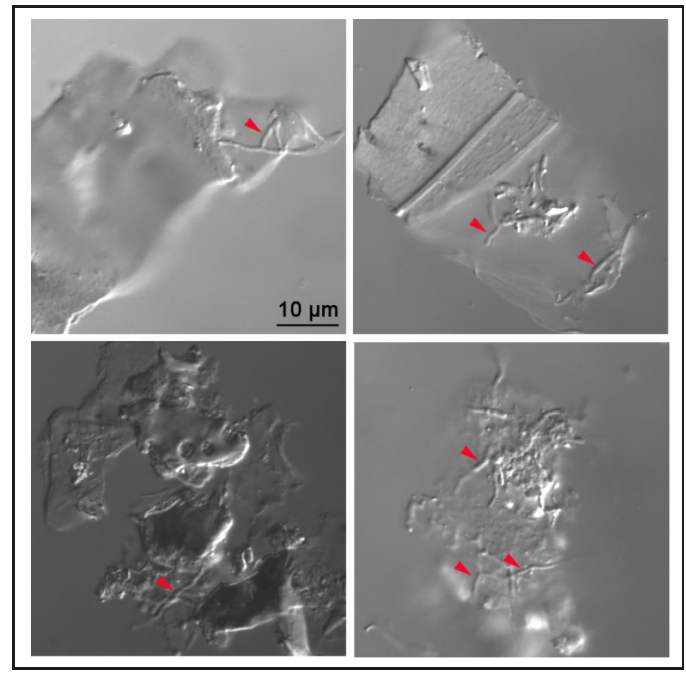

Fig. 4. Microscopic observation of Streptomyces mycelium on lignocellusosic residues. A few microliters of cultures were observed using a microscope equipped with Nomarski optics. Red arrows indicate Streptomyces mycelium adhering to the surface of the lignocellulosic residues.

the various carbon sources. Gas chromatography revealed that the FA detected were the same for the three monosaccharides tested. According to their retention times, mostly branchedchain FA, anteiso-C15:0 and iso-C16:0, were identified, as previously described in the literature (Fig. 3D) (Arabolaza et al., 2008, 2010). Because FAs were also present in the lignocellulosic biomass (C14:0, C16:0, and C16:1), the latter could not be used for the evaluation of bacterial biomass production using lignocellulosic samples for growth.

\subsubsection{Cultures on rapeseed and sunflower samples}

Streptomyces cultures on 1-mm lignocellulosic samples (raw substrates, two independent cultures) and on residues obtained after extractions (one culture for each extraction) were performed. To assess the performance of the conversion of the carbon sources into lipids, culture was also performed on a reference medium containing arabinose, a carbon source known to be favorable for bacterial growth. After inoculation with the same amount of $S$. lividans spores, a negative control was collected for each substrate to perform fatty acid quantification at the starting point (Tab. 2). Cultivation was carried out for 6 days at $30{ }^{\circ} \mathrm{C}$. Microscopic observation of the cultures revealed that the mycelium of Streptomyces adhered to the lignocellulosic substrate (Fig. 4) and consequently that it would 
not be possible to separate the Streptomyces from the lignocellulosic substrate for further biochemical analysis.

Quantification of total FA was performed on the whole cultures after transmethylation of the freeze-dried samples. C14:0, C16:0, and C16:1 FA were excluded from the analysis because they were common to both bacteria and lignocellulosic substrates. Some, C14:0 and C16:0, also seemed to be used as substrates by Streptomyces. The C12:0 FA was used as the internal standard for quantification because it was absent from both bacterial and lignocellulosic materials. First, it was observed that Streptomyces was able to use all of the lignocellulosic samples for growth, as an increase in the total bacterial FA content was observed between the negative control and the 6-days cultures (Tab. 2). Depending on the lignocellulosic sample used, the FA production ranged between $19 \%$ and $44 \%$ of the production obtained with the reference substrate, arabinose. Among the samples tested, the best performance was obtained with the unextracted Sun 1 sample. This result can be explained by the specifically low lignin content of this sample (14\%, versus $17 \%$ for the other samples). Indeed, because of their barrier properties and high content of ether bonds, the lignins present in the substrates were expected to limit the access of microorganisms to cellulose and hemicelluloses. The advantage of the Sun1 sample was lost after water extraction (Tab. 2), suggesting the water-extractible compounds present in this sample played a positive role in promoting bacterial growth. The absence of any difference between the water extraction residues and water-ethanol extraction residues for all samples indicated that the small proportion of ethanol-soluble compounds present in the samples did not affect growth or lipid production (Tab. 2).

\section{Conclusions}

Sunflower stalks and rape straw are two agricultural byproducts of interest but far less investigated until know than other lignocellulosic products. In this paper, we have provided novel information on the composition and lignin structure of these feedstocks which turned out to be very similar. Their lignins have high $\beta$-O-4 bond content compared to other angiosperms, which is an advantage with respect to lignin depolymerization process. For the first time, this pioneer work revealed that lignocellulosic products originating from oleaginous crops could be used as substrates for bacterial growth and production of lipids and fatty acids of interest in the actual context of green chemistry.

Acknowledgements. We thank Imen Chaieb and Alexandre Cukier for their technical assistance. This project received financial support from PRES UniverSud (2011/11/PB/N²31) and from Organisation Nationale Interprofessionnelle des Graines et Fruits Oléagineux (ONIDOL 920P00 contract).

\section{Competiting interests}

The authors declare that they have no competing interests.

\section{References}

Alvarez HM, Steinbuchel A. 2002. Triacylglycerols in prokaryotic microorganisms. Appl. Microbiol. Biot. 60: 367-376.

Alvarez HM, Mayer F, Fabritius D, Steinbuchel A. 1996. Formation of intracytoplasmic lipid inclusions by Rhodococcus opacus strain PD630. Arch. Microbiol. 165: 377-386.

Antai SP, Crawford DL. 1981. Degradation of softwood, hardwood, and grass lignocelluloses by two streptomyces strains. Appl. Environ. Microb. 42: 378-80.

Arabolaza A, Rodriguez E, Altabe S, Alvarez H, Gramajo H. 2008. Multiple pathways for triacylglycerol biosynthesis in Streptomyces coelicolor. Appl. Environ. Microbiol. 74: 25732582.

Arabolaza A, D'Angelo M, Comba S, Gramajo H. 2010. FasR, a novel class of transcriptional regulator, governs the activation of fatty acid biosynthesis genes in Streptomyces coelicolor. Mol. Microbiol. 78: 47-63.

Blazeck J, Hill A, Liu L, et al. 2014. Harnessing Yarrowia lipolytica lipogenesis to create a platform for lipid and biofuel production. Nat. Commun. 5: 3131.

Boon E, Struik PC, Engels FM, Cone JW. 2012. Stem characteristics of two forage maize (Zea mays L.) cultivars varying in whole plant digestibility. IV. Changes during the growing season in anatomy and chemical composition in relation to fermentation characteristics of a lower internode. NJAS-Wagen. J. Life Sci. 59: 13-23.

Caparrós S, Ariza J, López F, Nacimiento JA, Garrote G, Jiménez L. 2008. Hydrothermal treatment and ethanol pulping of sunflower stalks. Bioresource Technol. 99: 1368-1372.

Comba S, Menendez-Bravo S, Arabolaza A, Gramajo H. 2013. Identification and physiological characterization of phosphatidic acid phosphatase enzymes involved in triacylglycerol biosynthesis in Streptomyces coelicolor. Microb. Cell. Fact. 12: 9.

Coze F, Gilard F, Tcherkez G, Virolle MJ, Guyonvarch A. 2013. Carbon-flux distribution within Streptomyces coelicolor metabolism: A comparison between the actinorhodin-producing strain M145 and its non-producing derivative M1146. PLoS One 8: e84151.

Crawford DL. 1978. Lignocellulose decomposition by selected streptomyces strains. Appl. Environ. Microbiol. 35: 1041-1045.

Davis JR, Sello JK. 2010. Regulation of genes in Streptomyces bacteria required for catabolism of lignin-derived aromatic compounds. Appl. Microbiol. Biot. 86: 921-929.

Davis JR, Goodwin LA, Woyke T et al.. 2012. Genome sequence of Amycolatopsis sp. strain ATCC 39116, a plant biomass-degrading actinomycete. J. Bact. 194: 2396-2397.

Dence CW, Lin SY. The determination of lignin. In: Lin SY, Dence CW, eds.. Methods in Lignin Chemistry. Heidelberg: Springer Verlag, 1992, pp. 33-61.

Deniset-Besseau A, Prater CB, Virolle MJ, Dazzi A. 2014. Monitoring triacylglycerols accumulation by atomic force microscopy based infrared spectroscopy in streptomyces species for biodiesel applications. J. Phys. Chem. Let.t 5: 654-658.

Garay LA, Boundy-Mills KL, German JB. 2014. Accumulation of high-value lipids in single-cell microorganisms: A mechanistic approach and future perspectives. J. Agr. Food. Chem. 62: 27092727.

Guerra A, Elissetche JP, Norambuena M, et al. 2008. Influence of lignin structural features on eucalyptus globulus kraft pulping. Ind. Eng. Chem. Res. 47: 8542-8549.

Jung HG, Casler MD. 2006. Maize stem tissues. Crop. Sci. 46: 17931800 . 
Kang KE, Jeong GT, Park DH. 2012. Pretreatment of rapeseed straw by sodium hydroxide. Bioproc. Biosyst. Eng. 35: 705-713.

Kosa M, Ragauskas AJ. 2012. Bioconversion of lignin model compounds with oleaginous Rhodococci. Appl. Microbiol. Biot. 93: 891-900.

Kurosawa K, Wewetzer SJ, Sinskey AJ. 2013. Engineering xylose metabolism in triacylglycerol-producing Rhodococcus opacus for lignocellulosic fuel production. Biotechnol. Biofuels. 6: 134.

Lapierre C, Pollet B, Rolando C. 1995. New insights into the molecular architecture of hardwood lignins by chemical degradative methods. Res. Chem. Intermed. 21: 397-412.

Le Marechal P, Decottignies P, Marchand CH, et al. 2013. Comparative proteomic analysis of streptomyces lividans wildtype and ppk mutant strains reveals the importance of storage lipids for antibiotic biosynthesis. Appl. Environ. Microb. 79: 5907-5917.

Liu Y, Zhang C, Shen X, et al. 2013. Microorganism lipid droplets and biofuel development. BMB. Rep. 46: 575-581.

Mathews SL, Pawlak J, Grunden AM. 2015. Bacterial biodegradation and bioconversion of industrial lignocellulosic streams. Appl. Microbiol. Biotechnol. 99: 2939-2954

Mazhari Mousavi SM, Hosseini SZ, Resalati H, Mahdavi S, Garmaroody RE. 2013. Papermaking potential of rapeseed straw, a new agricultural-based fiber source. J. Clean. Prod. 52: 420424.

Menon V, Rao M. 2012. Trends in bioconversion of lignocellulose: Biofuels, platform chemicals \&amp; biorefinery concept. Prog. Energy. Combust. 38: 522-550.
Mood HS, Golfeshan AH, Tabatabaei M, et al. 2013. Lignocellulosic biomass to bioethanol, a comprehensive review with a focus on pretreatment. Renew. Sustain. Energy Rev. 27: 77-93.

Octave S, Thomas D. 2009. Biorefinery: Toward an industrial metabolism. Biochimie 91: 659-64.

Olukoshi ER, Packter NM. 1994. Importance of stored triacylglycerols in Streptomyces: Possible carbon source for antibiotics. Microbiology 140: 931-943.

Somerville C, Youngs H, Taylor C, Davis SC, Long SP. 2010. Feedstocks for Lignocellulosic Biofuels. Science 329: 790-792

Vetrovsky T, Steffen KT, Baldrian P. 2014. Potential of cometabolic transformation of polysaccharides and lignin in lignocellulose by soil Actinobacteria. PLoS One 9: e89108.

Xiong X, Wang X, Chen S. 2012. Engineering of a xylose metabolic pathway in Rhodococcus strains. Appl. Environ. Microbiol. 78: 5483-5491.

Zhang Y, Culhaoglu T, Pollet B, et al. 2011. Impact of lignin structure and cell wall reticulation on maize cell wall degradability. J. Agr. Food. Chem. 59: 10129-10135.

Zhao XB, Zhang LH, Liu DH. 2012. Biomass recalcitrance. Part I: the chemical compositions and physical structures affecting the enzymatic hydrolysis of lignocellulose. Biofuels Bioprod. Biorefining 6: $465-482$.

Ziebell AL, Barb JG, Sandhu S, et al. 2013. Sunflower as a biofuels crop: An analysis of lignocellulosic chemical properties. Biomass. Bioenergy 59: 208-217.

Cite this article as: Thierry Dulermo, Fabien Coze, Marie-Joëlle Virolle, Valérie Méchin, Stéphanie Baumberger, Marine Froissard. Bioconversion of agricultural lignocellulosic residues into branched-chain fatty acids using Streptomyces lividans. OCL 2016, 23 (2) A202. 